\title{
SPATIAL DISTRIBUTION OF THERMAL STRESSES IN IRAN BASED ON PET AND UTCI INDICES
}

\author{
Mohammadi, B. ${ }^{1 *}-$ GHOLIZADEH, M. H. ${ }^{1}-$ AliJAni, B. ${ }^{2}$ \\ ${ }^{I}$ Department of Climatology, Faculty of Natural Resources, University of Kurdistan \\ Sanandaj, Iran \\ ${ }^{2}$ Center of Excellence for Spatial Analysis of Environmental Hazard, Kharazmi University \\ Tehran, Iran \\ *Corresponding author \\ e-mail: b.mohammadi@uok.ac.ir; phone: 98-918-877-5160 \\ (Received $9^{\text {th }}$ Jun 2018; accepted $1^{\text {st }}$ Aug 2018)
}

\begin{abstract}
Cognition of the bioclimatic conditions in any place can be the first step in conducting many environmental studies. This study was performed with the aim of determining the thermal stress of Iran. For this purpose, the daily data of the climatic variables in 288 synoptic stations were prepared from the Iran Meteorological Organization during the period 1981-2010. First, the bioclimatic conditions in each of the stations were calculated based on UTCI (Universal Thermal Climate Index) and PET (Physiologically Equivalent Temperature) indices. Then, using the thermal stress of 288 synoptic stations, the bioclimatic conditions throughout Iran were interpolated using a Simple Kriging method. The results of this study showed that the bioclimatic conditions are immensely varied spatially and temporally, such that in specific times all bioclimatic conditions can be seen in Iran. Also, during the year, each place can experience different bioclimatic conditions. Based on UTCI, extreme cold and extreme heat stress are the only bioclimatic conditions that do not exist during the year. However, based on PET, all bioclimatic conditions exist during the year. Also July and January, respectively, are the hottest and coldest months of the year. Based on UTCI in April, October and November, more than $70 \%$ of Iran has comfortable conditions, whereas PET showed that in March and October 24.6 and 23.7\% experienced comfortable conditions respectively. It seems that the obtained results of PET index have high efficiency in relationship with UTCI index to show Iran's bioclimatic conditions.
\end{abstract}

Keywords: applied climatology, bioclimatic conditions, climatic comfort, human heat balance, extreme climatic conditions

\section{Introduction}

Climate and weather conditions are the most important components of the environment. Atmospheric conditions can have an effect on some activities and even create restrictions in our lives. Identification and understanding the weather conditions in any place is inevitable and necessary. It is clear that there is no place in the world experiencing favourable conditions and thermal comfort throughout the year. Nowadays, there has been much interest in the study of differentiation of bioclimatic conditions in outdoor spaces (Nikolopoulou, 2004; Geletič et al., 2018). Most of the research performed in different countries has been focusing on aspects such as the relations between thermal comfort, microclimate, behavior and use of place and spatial variation (Nikolopoulou and Lykoudis, 2006 and 2007; Thorsson et al., 2007; Kántor et al., 2012a, b). Such research is often carried out because of climate change and increased occurrence of heat stress in the earth's surface (Frich et al., 2002; Givoni et al., 2003; Matzarakis et al., 2013). An important use of bioclimatic studies is energy management and architecture. In many parts of Iran, architecture is designed to harmonize with the climate (Pourvahidi and Ozdeniz, 2013). In general, for 
comprehensive and sustainable development, environmental studies, especially bioclimatic studies are very important. In the past years, many indices on different aims and goals were developed to assess the suitability of climate for tourism activities and thermal stress issues including adaptation factors (Morgan et al., 2000; Maddison, 2001; Lise and Tol, 2002; Potchter et al., 2018). The recognition of human bioclimatic comfort in geographical areas is important for the planning of tourism (Matzarakis, 2006; Kovács et al., 2017). It could also help in the planning of building and housing, architectural patterns and the use of natural attractions of ecotourism in environmental planning (Ramazani Gourbi, 2010; Milošević et al., 2016).

The evaluation of bioclimatic conditions and atmospheric variables in each place can be used to choose the best time and place to travel, requirements that are important for tourism purposes (Caliskan et al., 2012). For example, research by Shakoor (2011) showed that in the Yazd province, the best season for tourists activities is autumn and the most ideal bioclimatic conditions with the emphasis on tourists health is seen in the Anar region (south west of Yazd province). Evaluation of the role of climate on tourism in the northwest of Iran, using the PET (Physiologically Equivalent Temperature) index showed that the months of June, July and August are in the comfortable category representing the most suitable months for tourism and tourist activities (Farajzadeh and Matzarakis, 2009). In another study using the Predicted Mean Vote (PMV) index the highest level of climatic comfort for Tabriz is in August, July and September, while the lowest value of climatic comfort is in November, December, January, February and March (Ghavidel Rahimi and Ahmadi, 2013). In another study, Eslami and Tirandaz (2011) showed up in their study that there are suitable conditions during the days, from May to November and during the night, from June to September in the Gilan province. There are several indicators to check the bioclimatic conditions. According to research by Cendrowska (2013) UTCI (Universal Thermal Climate Index) compared to the PET index is more efficient in assessing the bioclimatic conditions of urban areas for tourism and recreational purposes. In addition, climatic conditions can affect the health and welfare of humans. For example cold or very hot weather types, especially in young people and children can aggravate respiratory diseases (Lecha Estela, 1998). Several studies on bioclimatic conditions in different regions have been carried out.

Most studies that have been done in this field in Europe and the United States have been centered on human health (Scott et al., 2004; Ruuhela et al., 2017; Basarin et al., 2018). For example, the role of the climate on mortality rates in US cities was studied by Kalkstein (2008). The Dadbakhsh et al. (2017) study was conducted to evaluate the relation between respiratory-related mortality and temperature in Shiraz, Iran. Heat stress in Greece stuadied by Matzarakis and Mayer (1997). In Austria, has been studied heat-related mortality in Vienna (Matzarakis et al., 2011). A similar study was conducted by Nastos and Matzarakis (2008) on Athens. Such studies in Japan, to assess the environmental effects and in particular the effect of weather conditions on human activities and behaviors have also been done (Ichinose et al., 2008; Matzarakis, 2008). Studies in this discipline have progressed in China, similarly to popular studies in Europe, although the climatological background and acclimation potential of the peoples of China are partially similar to those of Japan.

Temperature and humidity are the important determinants of the bioclimatic conditions in any place. In addition to these two variables, wind speed, cloudiness and vapor pressure have an important role in our sense of climatic conditions. Though, each person is affected by a series of climatic variables simultaneously, their perception, 
feeling and response to these factors, however, due to physiological characteristics and coverage, are different (Lin et al., 2011). The review of a number of recent studies has shown that identification of bioclimatic regions has become an attractive issue worthy of investigation. These studies were focusing on tourism activities, diseases and health (Matzarakis, 2006). In this study, bioclimatic zones of Iran were identified by UTCI and PET indices. These indices are the best indicators used to assess the bioclimatic conditions in all climatic regions (Richards and Havenith, 2007; Bröde et al., 2009; Matzarakis et al., 1999).

The main purpose of current research is study of the bioclimatic conditions of Iran using PET and UTCI indexes. In fact, the obtained results of research can be the foundation of other research including planning of building and housing, architectural patterns, ecotourism, health, and so on. It is pinpointed that the two mentioned indexes rarely have been performed to show the bioclimatic conditions of Iran based on monthly scale in previously. Therefore, the characteristics and scope of each area based on bioclimatic regions were evaluated and final results of both indices were compared.

\section{Materials and methods}

In this study, the bioclimatic conditions in 288 synoptic stations of Iran based on the PET and UTCI indices were evaluated. However, these stations studied, did not have the statistical period equal. For example, Tehran, Isfahan, Tabriz, Mashhad and some old stations had a statistical period of more than 30 years, while in some other stations; the length of the survey period was less than 10 years.

Therefore, due to the inequality of the length of the study period, their long-term average daily was used. If the station has daily 10-year data, the long- term daily average of that station is calculated based on 10 years. For stations with more or less data, the same calculations have been done. In fact, in this study have been used longterm average daily data and maps provide with this data.

Atmospheric variables including average temperature, wind speed, relative humidity, cloudiness, and water vapor pressure were used. A database of meteorological variables mentioned was created for each station on a daily basis. After calculating the bioclimatic conditions of each station on daily, the long-term average daily thermal stress was calculated. Then, using interpolation techniques, bioclimatic conditions in Iran was estimated. The PET and UTCI indices were calculated by RayMan and BioKlima software respectively. Both indices can be calculated by several meteorological variables manually. But manual calculations are often difficult and very complex. Therefore, in most bioclimatic indices related software are often used in these cases (Mohammadi and Karimi, 2017). In this research, the homogeneity of the data was done using a Kolmogorov-Smirnov test .The data used were normal distribution, so their homogeneity was confirmed. The data used was obtained from the Meteorological Organization of Iran (Fig. 1).

Usually studies carried out in the field of bioclimatic conditions are in two different groups; bioclimatic conditions in outdoor and indoor spaces. Theoretically, the same indicators that the study of thermal stress indoors (climate discussion of architecture) are used, can also be used in open spaces of thermal stress. But the indices used for any geographic environment should be precisely identified. In fact, in evaluating thermal stress in outdoor spaces, many climate variables are not in the control of the researcher. So to solve this problem, the UTCI and PET, with the aim of a better assessment of 
thermal stress for the outdoors, were presented. In this study, to investigate thermal conditions of Iran, two indices (UTCI and PET) as the biometeorological indices based on the human heat budget are applied (Cendrowska, 2013). In fact, UTCI offers a better portrayal of biothermal conditions for human beings compared to other indices Temperature Effective (TE), Wet Bulb Globe Temperature (WBGT), Heat Stress Index (HIS), Wind Chill Temperature (WCT), Physiological Subjective Temperature (PST) and Physiological Strain (PhS) (Blażejczyk et al., 2012). Many variables are used to calculate and estimate this index. In addition to climatic variables, some personal variables such as metabolic rate and thermal resistance of clothes, was chosen. Another benefit of using PET and UTCI indices is their calculating units $\left({ }^{\circ} \mathrm{C}\right)$. Calculation in degrees Celsius creates a better understanding of these indices by experts in the fields of energy management, health and environmental planing (Lin and Matzarakis, 2008). To calculate the UTCI index, variables of air temperature $\left({ }^{\circ} \mathrm{C}\right)$, relative humidity $(\%)$, vapor pressure $(\mathrm{hPa})$, wind speed $(\mathrm{m} / \mathrm{s})$ and the sun altitude (degree), during the period 1981-2010, were used. Therefore, a database of these variables for each of the stations was prepared to a dimension of $365 * 5$. In this database, 5 is the number of variables and 365 is also the number of days of the year. For each station, bioclimatic conditions of Iran were calculated individually. Although UTCI index can be calculated by complex equations, in this study Bioklima 2.6 software was used to assess of thermal stresses. Different values of the UTCI have been classified according to thermal stress (Table 1). All steps for calculating the UTCI index were also performed for the PET index. The PET Index is one of the best indicators that based on the human energy balance equation (Matzarakis et al., 1999; Gulyas and Matzarakis, 2007; Charalampopoulos et al., 2013). The results of this index can be displayed as bioclimatic maps. The PET index is appropriate to evaluate the bioclimatic conditions in different geographical regions (Gulyas, 2005; Matzarakis et al., 2013). In this research, air temperature $\left({ }^{\circ} \mathrm{C}\right)$, relative humidity $(\%)$, average wind speed $(\mathrm{m} / \mathrm{s})$, and cloudiness (Octas) were used to calculate PET values for Iran.

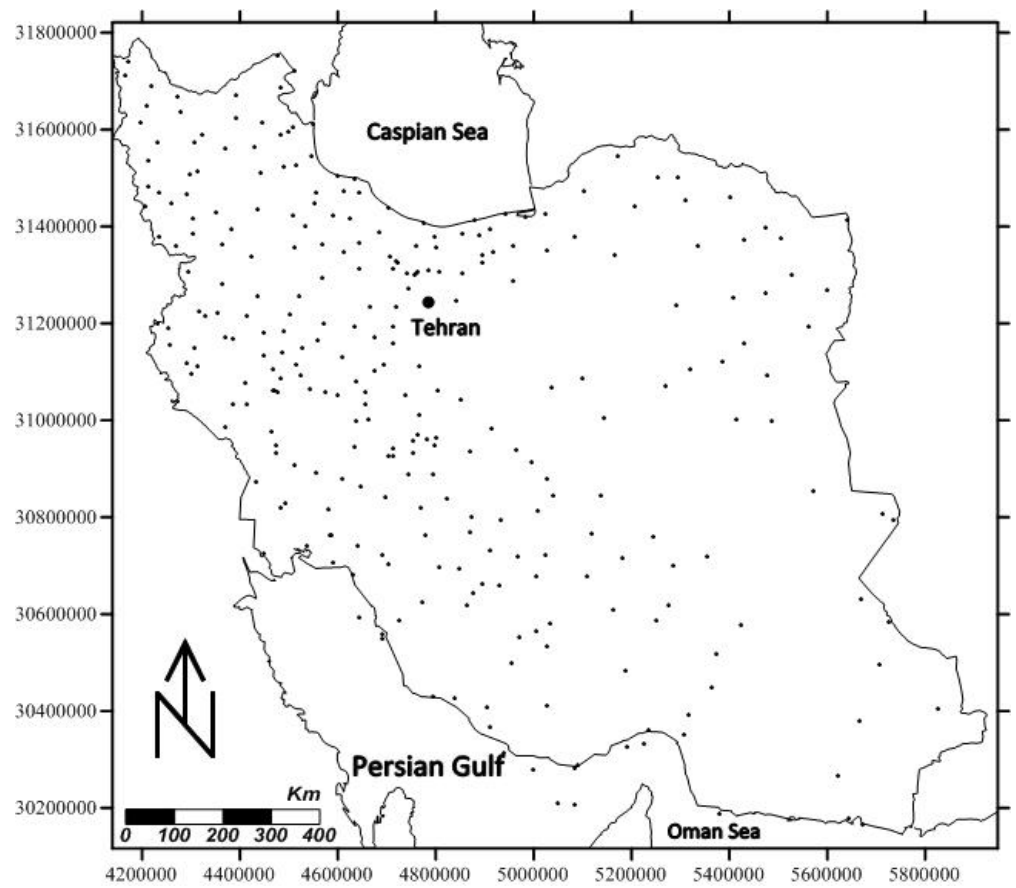

Figure 1. The geographic distribution of 288 synoptic stations in Iran 
Table 1. Ranges UTCI and of PET indices for different grades of thermal stress and thermal perception by human beings (Ketterer and Matzarakis, 2012)

\begin{tabular}{c|c|c|c}
\hline \multicolumn{2}{c|}{ Thermal stress based on UTCI index $\left({ }^{\circ} \mathbf{C}\right)$} & \multicolumn{2}{|c}{ Thermal perception based on PET index $\left({ }^{\circ} \mathbf{C}\right)$} \\
\hline Extreme heat stress & above +46 & Very hot & below 4 \\
Very strong heat stress & +38 to +46 & Hot & 4 to 8 \\
Strong heat stress & +32 to +38 & Warm & 8 to 13 \\
Moderate heat stress & +26 to +32 & Slightly warm & 13 to 18 \\
No thermal stress & +9 to +26 & Comfortable & 18 to 23 \\
Slight cold stress & +9 to 0 & Slightly cool & 23 to 29 \\
Moderate cold stress & 0 to -13 & Cool & 29 to 35 \\
Strong cold stress & -13 to -27 & Cold & 35 to 41 \\
Very strong cold stress & -27 to -40 & Very cold & above 41 \\
Extreme cold stress & below -40 & - & - \\
\hline
\end{tabular}

Due to the complexity of the calculations, in this study, PET and UTCI indices were calculated using RayMan 1.2 and BioKlima 2.6 software respectively.

The PET index is calculated as follows in several stages:

- In the first step body temperature must be calculated with MEMI (Munich Energy balance Model for Individuals) model based on meteorological parameters.

- In the second step the calculated values of mean skin temperature and core temperature imported into the MEMI model and energy balance equation for air temperature based on $T_{a}$ (with $v=0.1 \mathrm{~m} / \mathrm{s}, V P=12 \mathrm{hPa}$ and $T_{m r t}=T_{a}$ ) dissolved. Eventually air temperature obtained is equivalent to the PET.

The UTCI is defined as the air temperature (t) of the reference condition causing the same physiological response as the actual condition. Thus, UTCI is the air temperature which would produce under reference conditions the same thermal strain as in the actual thermal environment. Therefore, with the help of the mathematical relation, the UTCI can be calculated:

\section{UTCI = CalcUTCI (temp, wind, mrt, hum)}

Where temp: air temperature $\left({ }^{\circ} \mathrm{C}\right)$; wind: wind speed $(\mathrm{m} / \mathrm{s})$; mrt: mean radiant temperature $\left({ }^{\circ} \mathrm{C}\right)$; hum: humidity ratio $(\%)$.

By calculating the bioclimatic conditions of all stations, two databases from output UTCI and PET indices with dimensions of $288 * 365$ were prepared. In this database, 365 and 288, respectively, are the numbers of days of the year and stations. One purpose of this research was the mapping of Iran's bioclimatic conditions. To draw these maps from the estimated heat stress, data of 288 of Iran's synoptic stations based on PET and UTCI were used. In fact, using thermal stress to calculate these stations, interpolation was performed. In the atmospheric and geographical field of numerical analysis, interpolation is a method of constructing new data points within the range of a discrete set of known data points. In some cases it may be the average value of a parameter to be estimated over an area. This average, by the Simple Kriging method 
will be calculated on different parts of that region and from their average the results will be achieved. Therefore, in this study, the Simple Kriging method was used to estimate Iran's bioclimatic conditions. In Simple Kriging, all input points are used to calculate each output pixel value. The output of a Simple Kriging method is a raster map. For each pixel in the output map, a value is calculated by an interpolation on input point values. Finally, based on this database, bioclimatic conditions in Iran were estimated. Thus, for each day throughout the country, a bioclimatic map was prepared. In addition to using monthly averages of bioclimatic conditions, bioclimatic maps were drawn.

\section{Results}

\section{Annual and seasonal differentiation of bioclimatic conditions}

Based on the UTCI index, Iran's bioclimatic conditions during the year showed, on average, a comfort bioclimatic condition prevailing in $45 \%$ of Iran. In total, $31.7 \%$ of Iran has gone towards a warming condition over the year (the moderate heat stress, strong and very strong heat stress). On the other hand, cold bioclimatic conditions (slight cold stress, moderate cold stress, strong cold stress and very strong cold stress) in $21.3 \%$ of Iran have been seen. It should be noted, according to UTCI, strong and very strong heat stress condition, did not prevail in any part of Iran over the year. Each of the bioclimatic conditions during different months of the year, have shown a different situation. So, strong cold stress and strong heat stress conditions have not been seen, at any time, in Iran. Other bioclimatic conditions, such as very strong cold stress, has been record in Iran, for both January (0.9\%) and February (0.2\%). Also a very strong heat stress condition has been determined in Iran, for June $(6.5 \%)$, July $(10.7 \%)$ and August (6.8\%). PET analysis on Iran's bioclimatic conditions during the year showed that, on average, a comfort bioclimatic condition has been experienced in $11.9 \%$ of Iran. In total, $55.6 \%$ of Iran has experienced warming conditions over the year (slightly warm, warm, hot and very hot). On the other hand, $32.5 \%$ of Iran has experienced cold conditions (low cold stress, cold stress, strong and very strong cold stress). It should be noted, according to this index, very cold and hot bioclimatic conditions, 3.5 and $15.1 \%$, respectively, are in the lowest and highest parts of Iran. In general, according to Table 2, we can say that each of the bioclimatic conditions during the year have shown a different situation. For example, comfortable and slightly warm conditions were seen throughout the year in Iran. Other bioclimatic conditions, like very cold, have been reported in Iran, during winter and autumn. Also a very hot condition has been experienced in Iran during spring and summer. Other conditions and affected zones in different seasons can be seen in Table 2 and Figure 2.

In general, in the annual assessment of PET and UTCI indices from Iran, significant differences were observed in thermal stress. Comparing Iran's annual differentiation of bioclimatic conditions based on mentioned indices, suggests that the PET index has a more reasonable estimate of Iran's thermal comfort compared to the UTCI index. Because Iran was located in the world's desert belt and also identified as an arid and semi-arid region, the thermal comfort does not dominate climatic conditions. Hence PET's assessment of Iran's thermal comfort is closer to the climatic reality. The difference in the quality of assessment of these indices can also be seen clearly in monthly maps. 

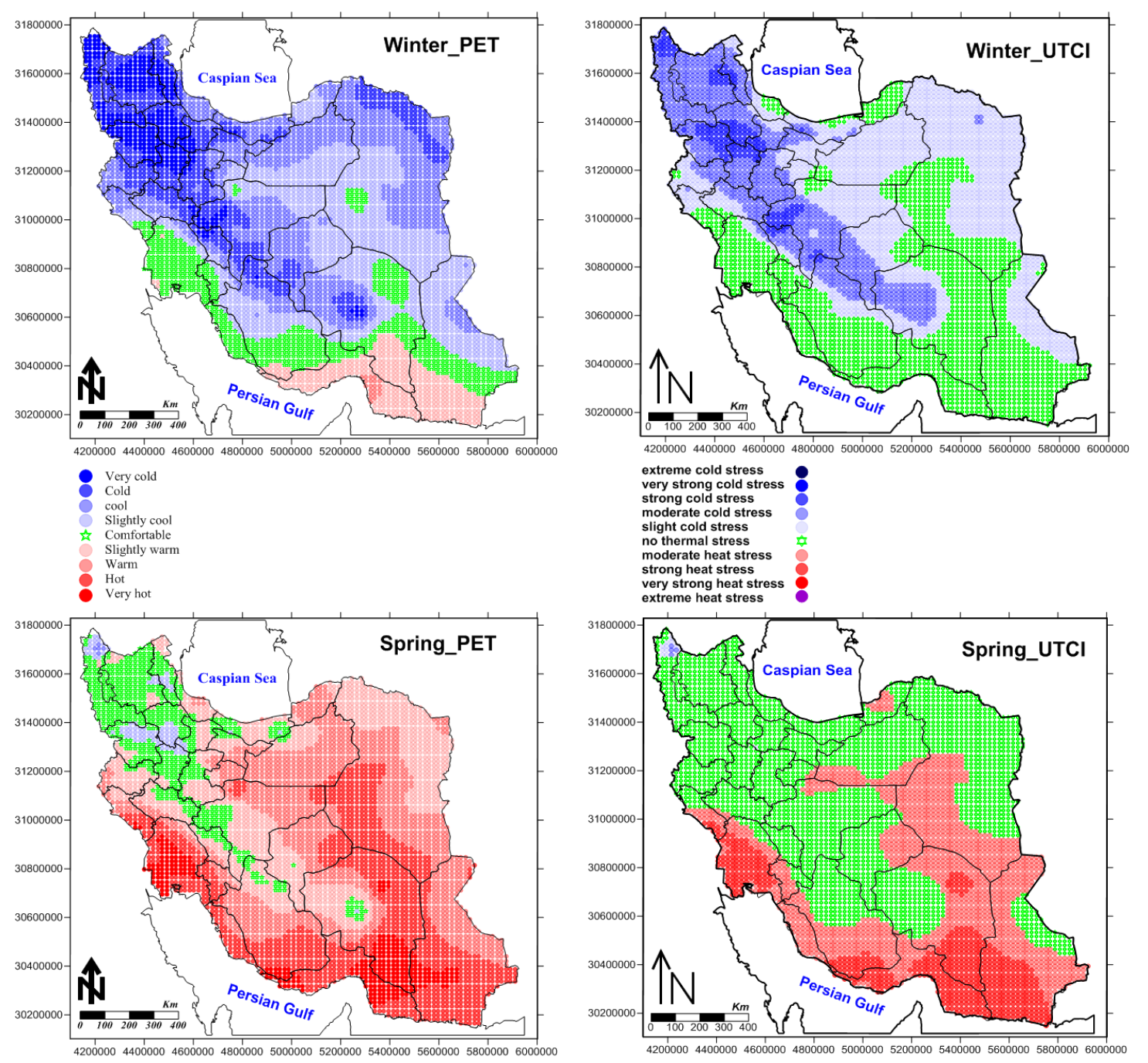

Very cold
Cold
cool
Slightly cool
th Comfortable
Slightly warm
Warm
Wot

Slightly warm
Hot

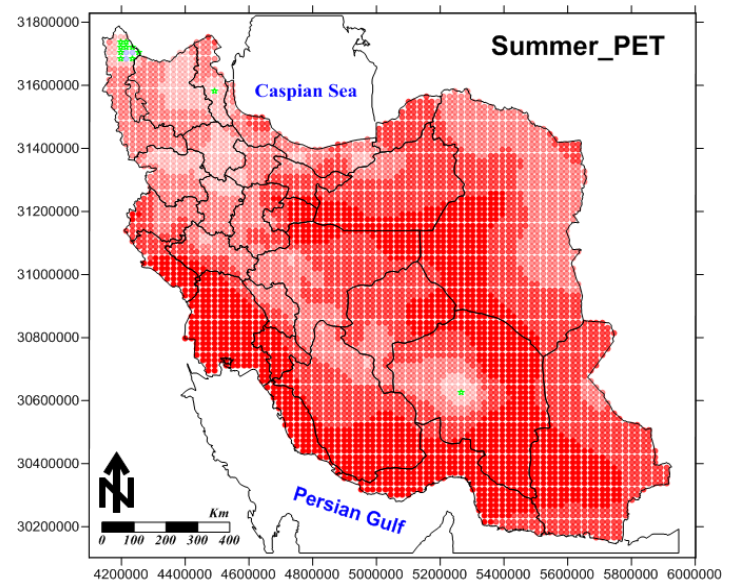

extreme cold stress

very strong cold stress

moderate cold stress

slight cold stress

no thermal stress
moderate heat stres

moderate heat stress
strong heat stress

very strong heat stress
extreme heat stress

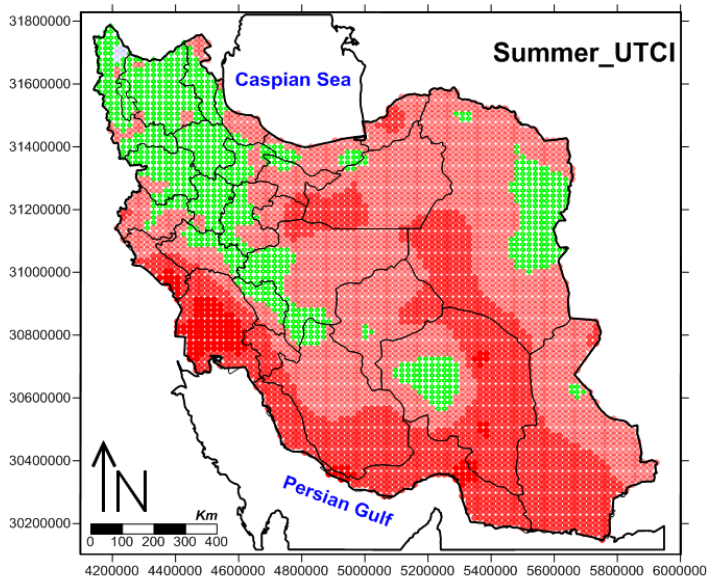

42000004400000
extreme cold stress

very strong cold stress
strong cold stress

moderate cold stress

slight cold stress

no thermal stress
moderate heat stres

moderate heat stress
strong heat stress

very strong heat stres
extreme heat stress

Slightly warm

Warm
Hot

APPLIED ECOLOGY AND ENVIRONMENTAL RESEARCH 16(5):5423-5445.

http://www.aloki.hu • ISSN 15891623 (Print) • ISSN 17850037 (Online)

DOI: http://dx.doi.org/10.15666/aeer/1605_54235445 

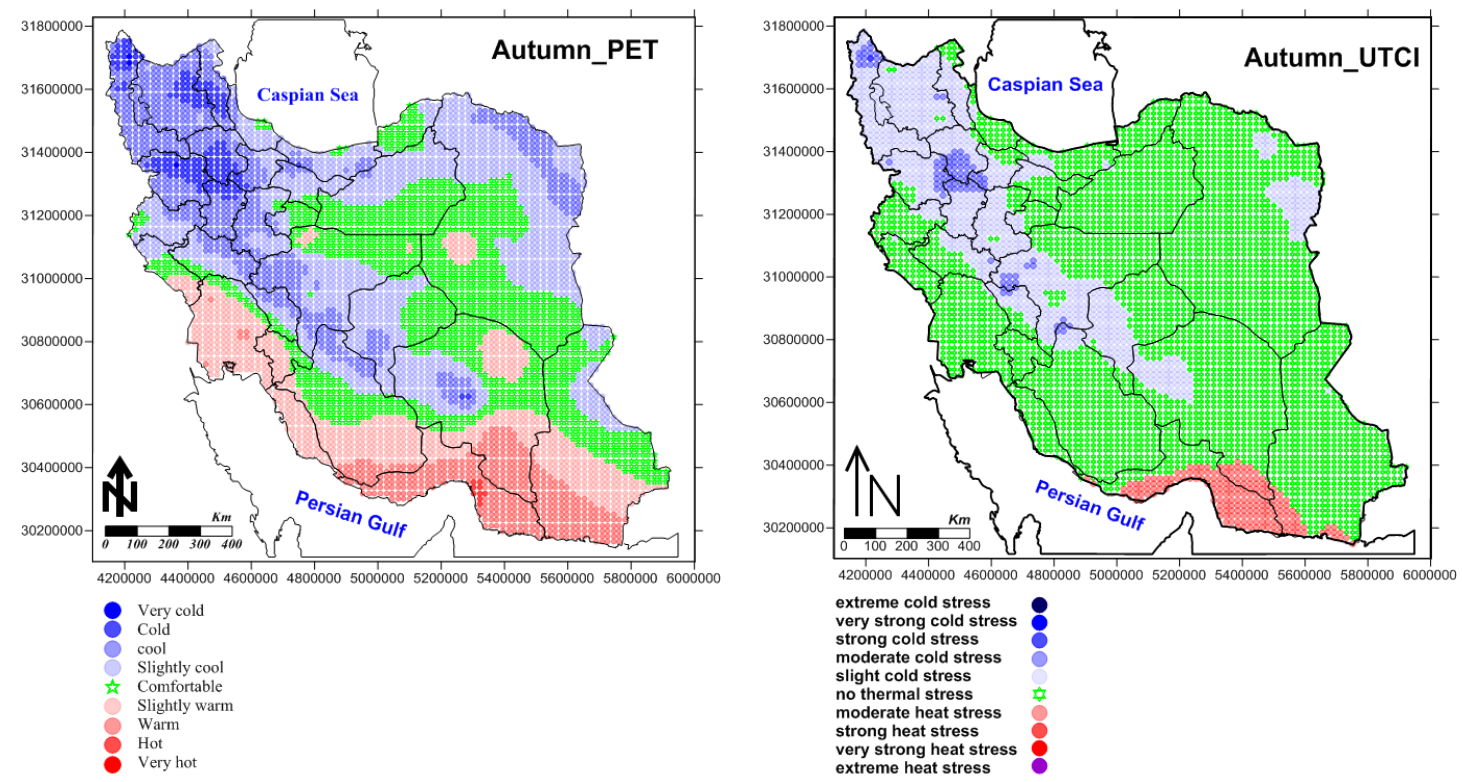

Figure 2. Iran's bioclimatic conditions in winter, spring, summer and autumn

Table 2. The spatial extent (percent of the territory of Iran) of various categories of thermal stress and thermal perception in Iran, mean seasonal values for the period 1981-2010

\begin{tabular}{c|c|c|c|c}
\hline UTCI & Winter & Spring & Summer & Autumn \\
\hline Extreme cold stress & 0.0 & 0.0 & 0.0 & 0.0 \\
Very strong cold stress & 0.4 & 0.0 & 0.0 & 0.0 \\
Strong cold stress & 4.9 & 0.0 & 0.0 & 0.4 \\
Moderate cold stress & 19.3 & 0.1 & 0.0 & 6.9 \\
Slight cold stress & 32.9 & 2.7 & 0.1 & 21.7 \\
No thermal stress & 42.3 & 52.0 & 22.5 & 63.1 \\
Moderate heat stress & 0.3 & 28.3 & 40.3 & 7.1 \\
Strong heat stress & 0.0 & 14.7 & 31.3 & 0.7 \\
Very strong heat stress & 0.0 & 2.2 & 5.8 & 0.0 \\
Extreme heat stress & 0.0 & 0.0 & 0.0 & 0.0 \\
\hline PET & Winter & Spring & Summer & Autumn \\
\hline Very cold & 10.5 & 0.0 & 0.0 & 3.5 \\
Cold & 14.4 & 0.1 & 0.0 & 7.5 \\
Cool & 26.9 & 4.0 & 0.0 & 17.5 \\
Slightly cool & 22.1 & 18.8 & 0.1 & 20.1 \\
Comfortable & 15.7 & 36.0 & 0.7 & 19.3 \\
Slightly warm & 8.9 & 61.8 & 7.7 & 17.1 \\
Warm & 1.5 & 74.9 & 23.5 & 9.9 \\
Hot & 0.0 & 60.8 & 35.1 & 4.8 \\
Very hot & 0.0 & 43.8 & 32.8 & 0.1 \\
\hline
\end{tabular}




\section{Monthly differentiation of bioclimatic conditions}

\section{January}

Studying the bioclimatic conditions of Iran by UTCI showed that extreme heat stress, strong and very strong heat stress, moderate heat stress and strong cold stress conditions in January, have not been experienced in Iran. In $27.4 \%$ of Iran's territory, any thermal stress has not been seen. In this month, southern and southwestern regions of Iran, as well as scattered parts of the Caspian Sea coasts do not have heat stress. In January, slight cold stress in large parts of Iran (37.8\% of Iran) was dominant. In addition, moderate cold stress, strong cold stress and very strong cold stress, with 25.6, 8.3 and $0.9 \%$, respectively, covered a considerable part of Iran in northern latitudes and higher elevations. In January, by reducing the height and latitude, Iran's bioclimatic conditions have changed to climatic comfort. Based on the PET index, Iran does not have warm, hot and very hot bioclimatic conditions in January. In this month, cold conditions are dominant from the south to the northwest and northeast of Iran. However, the northwest of Iran, Kurdistan and Hamadan provinces are coldest places in Iran. Of course, on along the northwest to the southeast of Iran to the center of Kerman province, also Alborz Mountains and some parts of northeast and north of Iran, cold conditions has been experienced. On the other hand, slight warmth is experienced only in some parts of Hormozgan, Sistan and Baluchistan provinces. Generally, in this month, cool, cold and very cold conditions, 32.3, 20.3 and $18.2 \%$, respectively, covered most parts of the country. Also, $10 \%$ of Iran was located in differentiation of bioclimatic conditions (Fig. 3).

\section{February}

Bioclimatic conditions of Iran in February revealed a very similar thermal stress to that of January. In this month, extreme heat stress, very strong heat stress, strong heat stress and moderate heat stress was not observed in Iran. In addition, extreme cold stress in any part of Iran cannot be seen. In this month, bioclimatic conditions with no thermal stress, compared to January, have shown a significant increase. The scope of areas without any thermal stress has increases from $27.4 \%$ in January to $33.2 \%$ in February. Slight cold stress in large parts of Iran $(37.7 \%)$ has not been experienced. In this month, the extent of areas under moderate cold stress, strong cold stress and very strong cold stress has been reduced. In February, very hot and hot conditions cannot be seen in Iran. Compared to January, the extent of the areas that had experienced cold conditions has reduced. As well as the extent of areas with differentiation of bioclimatic conditions, slightly warm and warm conditions increased. From the southwest to the southeast of Iran, thermal comfort and slightly warm conditions are prevalent. In this month, in the highlands, as well as high latitude, there are cold conditions. In February such as in January, the northwest experienced colder conditions than other regions of Iran. Cool, cold and slightly cool conditions were experienced in 27.5, 24.4 and $16.5 \%$ of Iran, respectively (Fig. 3).

\section{March}

In March, extreme cold stress and very strong cold stress in the territory of Iran had not been seen. Compared to the months of January and February, cold stress in March is dominant in smaller parts of Iran. Therefore, it can be said that in March the beginning 
of heat stress become evident in Iran, meaning that in March, the comfort conditions, compared to January and February, have been experienced in more parts of Iran. In fact, thermal comfort in March is the most abundant bioclimatic conditions of Iran. These conditions prevailed in $66.2 \%$ of the territory of Iran. By reducing the height and latitude, cold stress conditions in Iran has declined. Also start of heat stress can be seen in the Persian Gulf and Southeast of Iran. There is an obvious difference among Iran's bioclimatic conditions in March compared to January and February. In March, the heat stress conditions in large parts of this country have developed. In other words, in this month, Iran was beginning to get out of the cold climatic conditions (slightly cool to very cold). There are cold and very cold conditions in less than $8 \%$ of Iran. In contrast, slightly cool, comfortable and cool conditions, have been experienced, in 25.5, 24.6 and $20.8 \%$ respectively, of Iran. In this month, more than $20 \%$ of Iran's climatic conditions tend to be warm. For example, areas that are in high latitudes and with greater height have experienced relatively colder bioclimatic conditions (Fig. 3).
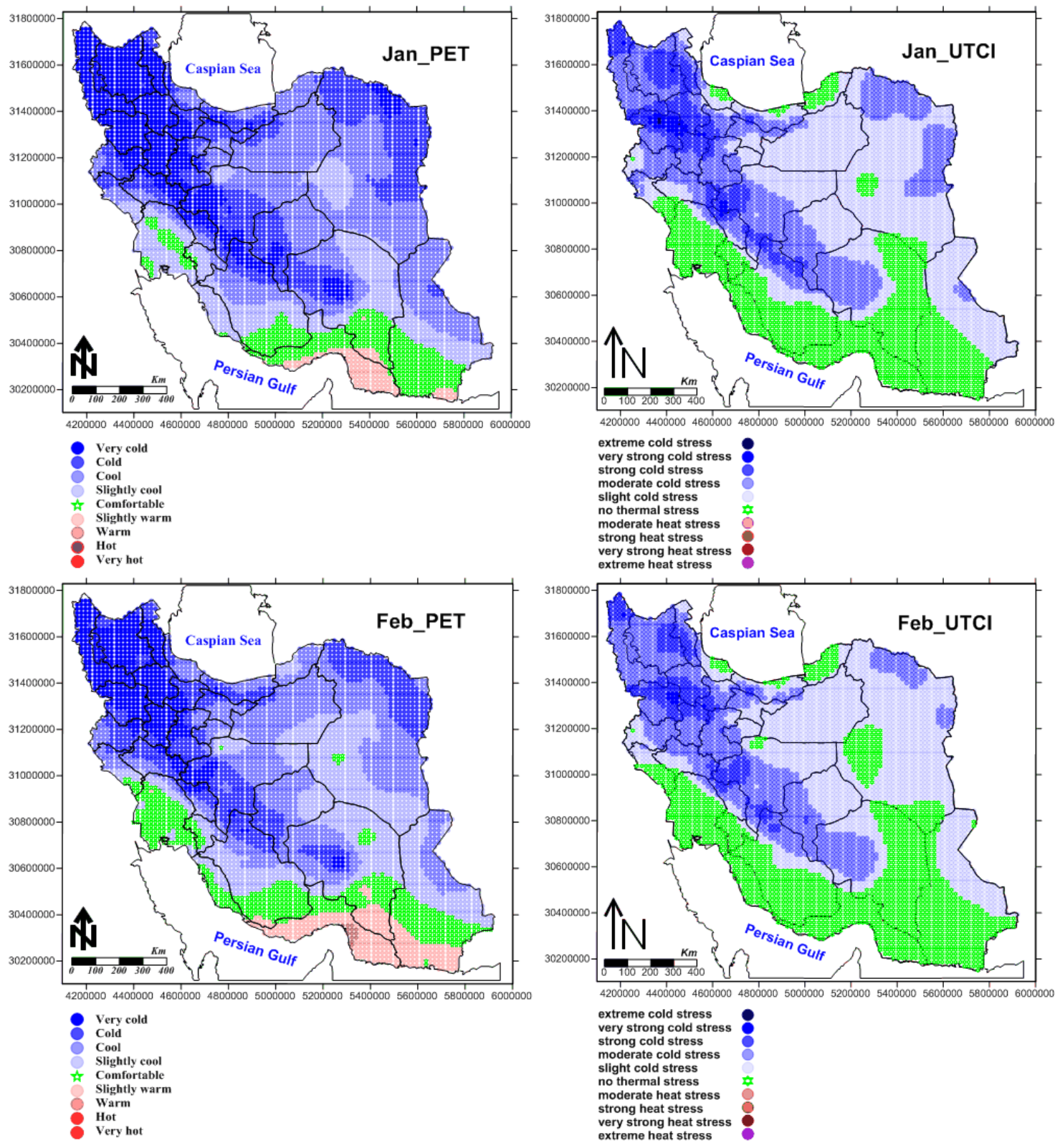

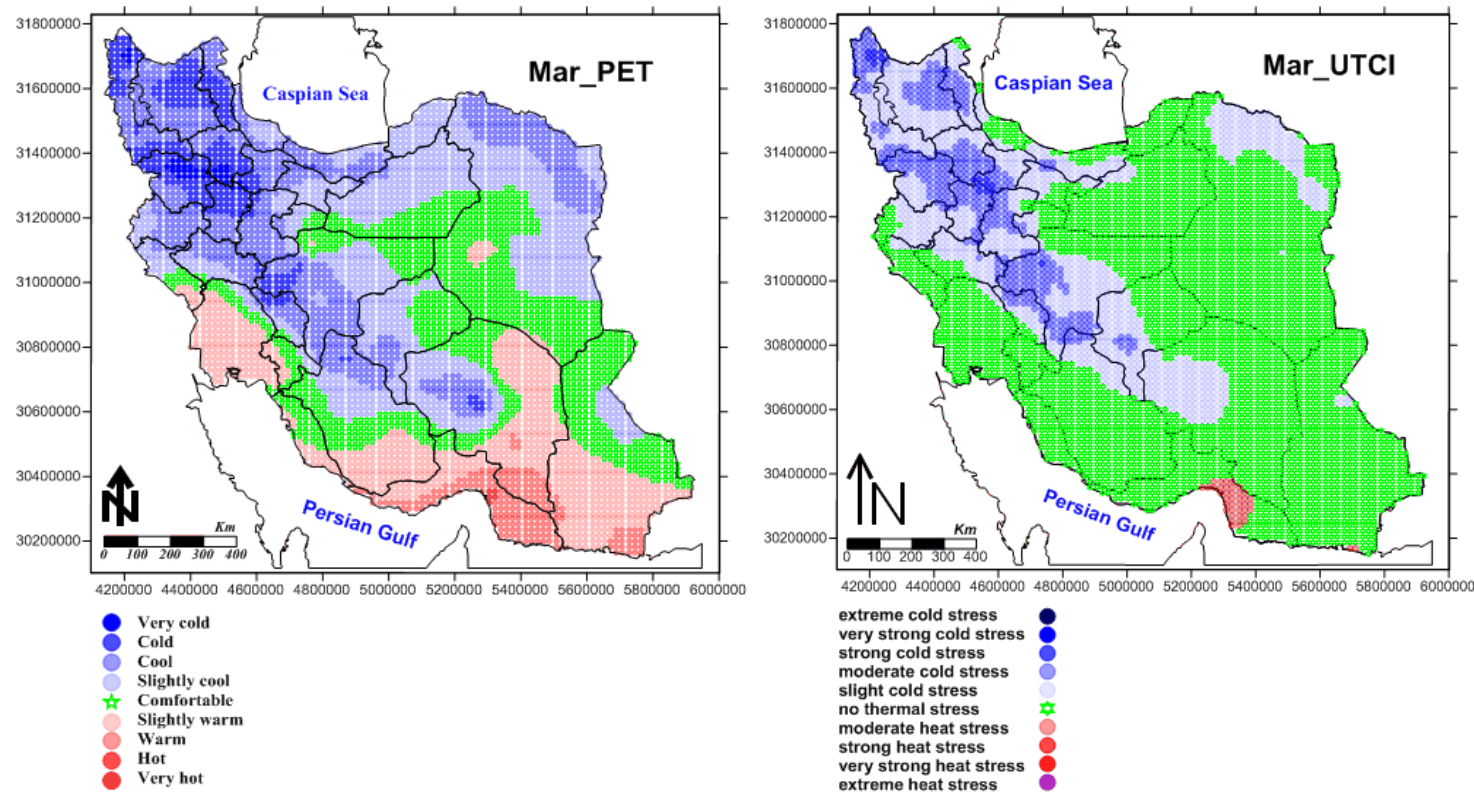

Figure 3. Iran's bioclimatic conditions in January, February and March

April

In April, bioclimatic conditions of extreme cold stress, very strong cold stress, strong cold stress, extreme heat stress, very strong heat stress and strong heat stress has not been seen in Iran. No thermal stress conditions in April, compared to the previous months (winter), in the wider parts have expanded. In this month, more than $76 \%$ of Iran has experienced no thermal stress conditions. The important point in this month is an increase in the range of moderate heat stress conditions that Iran has experienced. Within $15.5 \%$ of Iran, there was moderate heat stress. The belt of the south, southeast, parts of the southwest of Iran as well as parts of Kerman province are in the territories of moderate heat stress. In this month, scattered parts of the Kurdistan province and also along the Zagros Mountains have cold stress. In April, Iran's bioclimatic conditions have changed compared to winter, especially in the months of January and February. In this month, severe bioclimatic conditions (very cold and very hot) are not experienced in Iran. In general, slightly cool, cool, cold conditions ruled about $20 \%$ of Iran's territory. Unlike March, in this month, the extent of the regions with climatic comfort is reduced. Warm conditions also extended in large areas of Iran. In this month slightly warm, warm and comfort to the respectively $28.8,23.1$ and $21 \%$ in the major part of Iran have been seen. Southern of Iran being the warmest in this month and the northwest of Iran to the Alborz and Zagros Mountains being the coolest parts of the country (Fig. 4).

May

Bioclimatic conditions prevailing in May show a significant increase in heat stress. In this month, only a small part in the northwest of Azerbaijan is experiencing slight cold stress. From the beginning of the year (from January to May) cold stress with different intensities is seen in a small region of Iran. The important point in this month is the reduction in areas affected by thermal comfort. From January to April, the extent 
of comfort conditions showed an increasing trend. This condition in Iran has shown a significant reduction (dropping from $76.6 \%$ in April to $54.6 \%$ in May). By contrast, moderate heat stress and strong heat stress were observed in 29.7 and $15.3 \%$ of Iran's territory. Therefore the warming trend of Iran in this month suddenly increased. In this month, in reduced elevation and latitude, heat stress has increased. In fact, large parts of central Iran and also Iran's southern tapes have experienced this situation. Iran's bioclimatic conditions in May, is very similar to April. In May, bioclimatic conditions of very cold, cold and cool have almost left Iran. Moreover, only $2.4 \%$ has experienced slightly cool conditions. Comfort condition in less than $15 \%$ (highlands and higher latitudes) has prevailed. Also for the first time, about $10 \%$ of Iran is in hot conditions. Hot, warm, and slightly warm conditions have covered Iran, 28.3, 23.4 and $22.1 \%$, respectively. In this month, only scattered parts of the northwest of Iran have slightly cool conditions (Fig. 4).
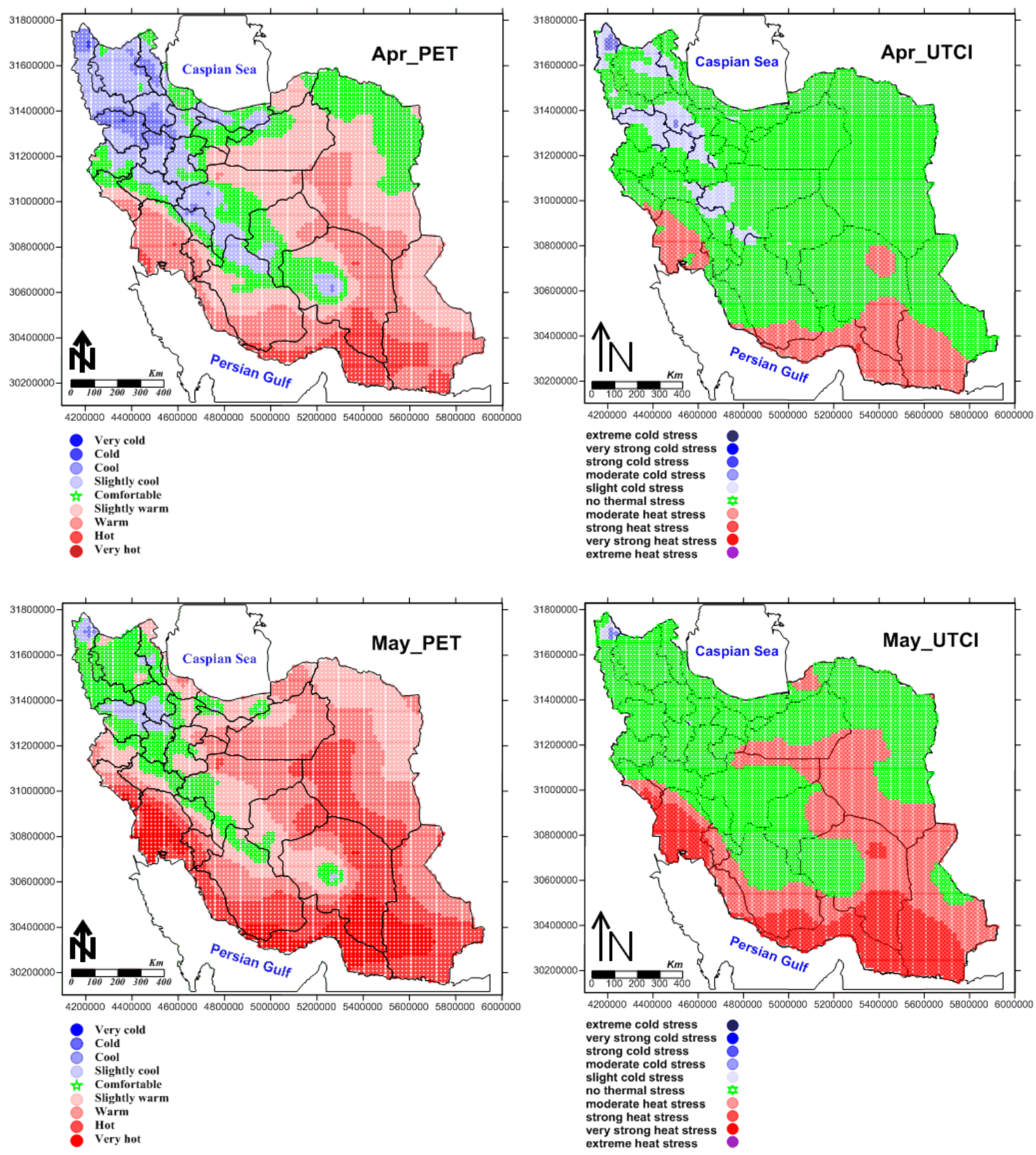

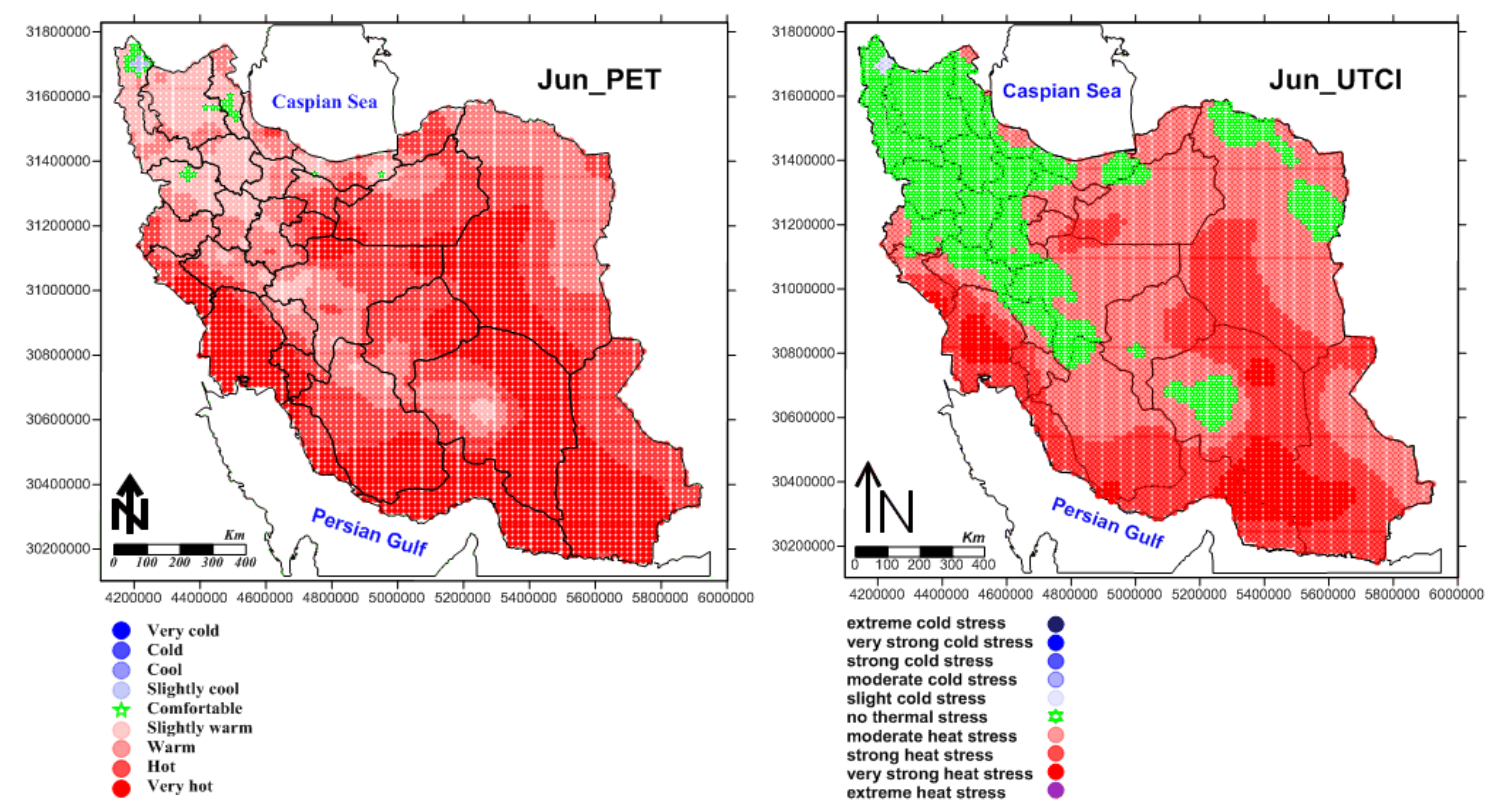

Figure 4. Iran's bioclimatic conditions in April, May and June

June

In June, almost all cold stress bioclimatic conditions in Iran have vanished based on the UTCI index. In only $0.1 \%$ of Iran slightly cold stress conditions prevailed. From the northwest of Iran to the south of Isfahan province, scattered areas in the northeast of Iran and the middle of Kerman province comfort conditions prevail. These areas include about $24.9 \%$ of Iran. Other parts of Iran are under the influence of moderate heat stress $(39.8 \%)$; strong heat stress $(28.7 \%)$ and very strong heat stress $(6.5 \%)$, respectively. Generally, in June, the severe heat stress can be seen. Heat stress in the lower latitude and longitude, as well as Iran's low-lying areas, is more than other regions. Based on the PET, very cold, cold, cool conditions have not been seen in Iran. However, there is a slightly cool condition in about $0.1 \%$ and thermal comfort in about $0.6 \%$ of a small part of the northwest of Iran. Thus, in more than $99 \%$ of Iran, warm conditions with different intensities have been reported. It should be noted that in the highlands and of course the higher latitude there is less intense heat. In this month, very hot, hot, and warm conditions are seen in 34.4, 30.6 and 23.5\%, respectively, of Iran (Fig. 4).

\section{July}

Iran's bioclimatic condition in July is similar to June. In July, almost no cold stress is seen in Iran. Less than $0.1 \%$ of the Iranian region has experienced slight cold stress conditions. However, there is a significant difference in July compared to June. Thermal stress in this month has declined to $7.8 \%$. Only in small parts of Iran, no thermal stress can be seen. In this month, more elevated areas and areas with higher latitude have experienced thermal comfort conditions. Reduced thermal stress and the lack of cold stress condition in this month, expanding heat stress condition with varying severity, have been confirmed. Overall, more than $90 \%$ of the region has experienced heat stress conditions with different intensities. The current bioclimatic conditions of this month, is a strong heat stress condition (42.2\% of Iran). Bioclimatic conditions of moderate heat 
stress with $38.3 \%$ and very strong heat stress with $10.7 \%$ prevailed in large parts of the country. The PET index showed that in July, no part of Iran experienced slightly cool, cool, cold and very cold conditions. In this month, the thermal comfort condition was experienced in only in $0.2 \%$ of Iran (a small part of the northwest of the country). Therefore, $99.8 \%$ of Iran's territory experienced warm conditions. Large parts of the country $(45.1,33.3$ and $18.9 \%$ ) were in very hot, hot, and warm conditions, respectively. Heat intensity in the higher places (Alborz and Zagros mountains) and the northwest is less than other parts of Iran (Fig. 5).

\section{August}

No significant changes can be seen in the bioclimatic conditions of Iran in August compared to July and June. In August, only $0.1 \%$ is under the influence of slight cold stress. Cold stress with more intensity like Jun and July cannot be seen in any part of Iran. In August, comfort conditions, compared to previous months, increased slightly. In this month, $13 \%$ of Iran, including parts of the northwest and northeast of the country, west of Isfahan province and central Kerman, experienced no thermal stress conditions. Increasing climatic comfort conditions (no thermal stress condition), on the one hand, and a reduction in the range of areas that have experienced very strong heat stress and strong heat stress on the other hand, indicates the relative cool air in Iran. In this month, very strong heat stress conditions are limited to $6.8 \%$. Also the strong heat stress conditions decreased to $35.1 \%$. In this month, the thermal stress condition reduction in the highlands and northern latitudes is remarkable. Based on the PET index, Iran's bioclimatic conditions in August are very similar to July. In this month $99.8 \%$ of Iran is experiencing hot conditions (with different intensities). In total, only $0.2 \%$ of Iran is in thermal stress and slightly cool conditions. In this month, cool, cold and very cold conditions in the scope of Iran cannot be seen. However, a significant difference is in the extent of very hot bioclimatic conditions between July and August. The extent of the hot condition in August (39.3\%) is lower than in July (45.1\%) in Iran. However, hot and warm conditions in August compared to July have increased significantly (Fig. 5).

\section{September}

Bioclimatic conditions in September showed that in many parts of Iran, the severity of heat stress is reduced. Contrary to June, July and August, very strong heat stress conditions in the territory of Iran have been eliminated. In addition, strong heat stress and moderate heat stress in comparison with the months before 16.5 and $37.6 \%$, respectively, has decreased. Among the bioclimatic conditions, no thermal stress conditions were experienced in $45.8 \%$ of the territory of Iran. An increase in the range of areas that have no thermal stress conditions on the one hand, and a reduction in the severity of heat stress on the other hand, represent a new stage entering Iran's bioclimatic conditions. In this month highlands (including the Zagros mountain range, Alborz and northeast of Iran) and also northern latitudes of Iran have bioclimatic comfort conditions (no thermal stress). In the lowlands and lower latitude, strong heat stress can be seen. Based on the PET index, the intensity of heat over Iran has reduced in September. In addition, comfort condition has expanded to 1.8\%. Along the Zagros and Alborz mountains, and generally highlands, heat with intensity is further reduced (Fig. 5). 

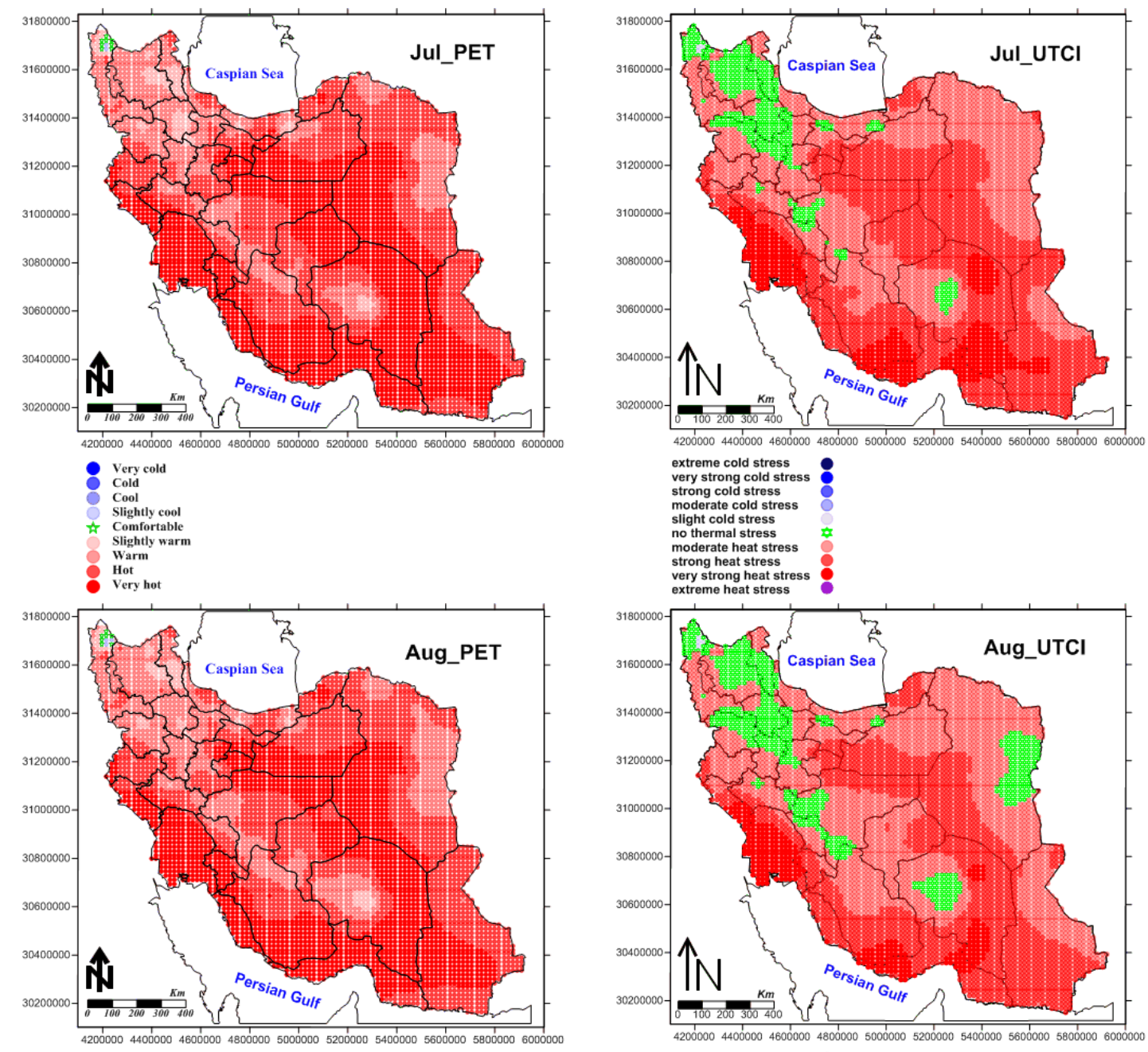

Very cold

\begin{tabular}{l} 
Cold \\
Cool \\
Slightly cool \\
Comfortable \\
Slightly warm \\
Warm \\
Hot \\
Very hot \\
\hline
\end{tabular}

extreme cold stress
very strong cold stress

strong cold stress
moderate cold stress

moderate cold stre

slight cold stress
no thermal stress

moderate heat stress
strong heat stress

strong heat stress
very strong heat stress

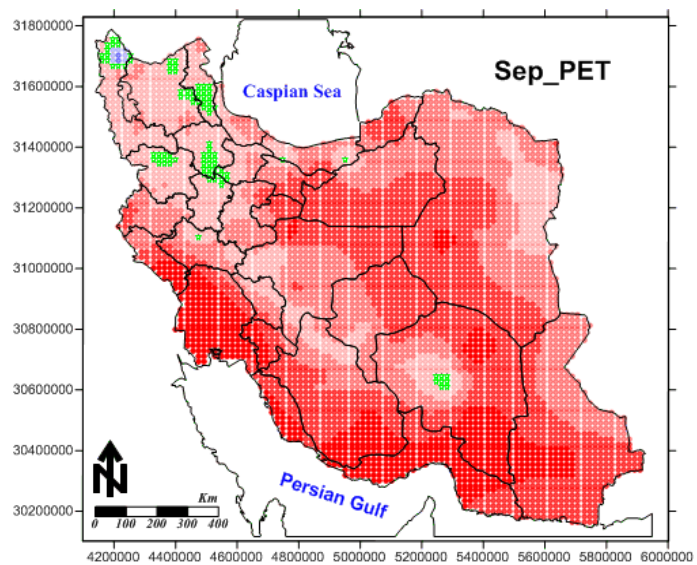

Very cold
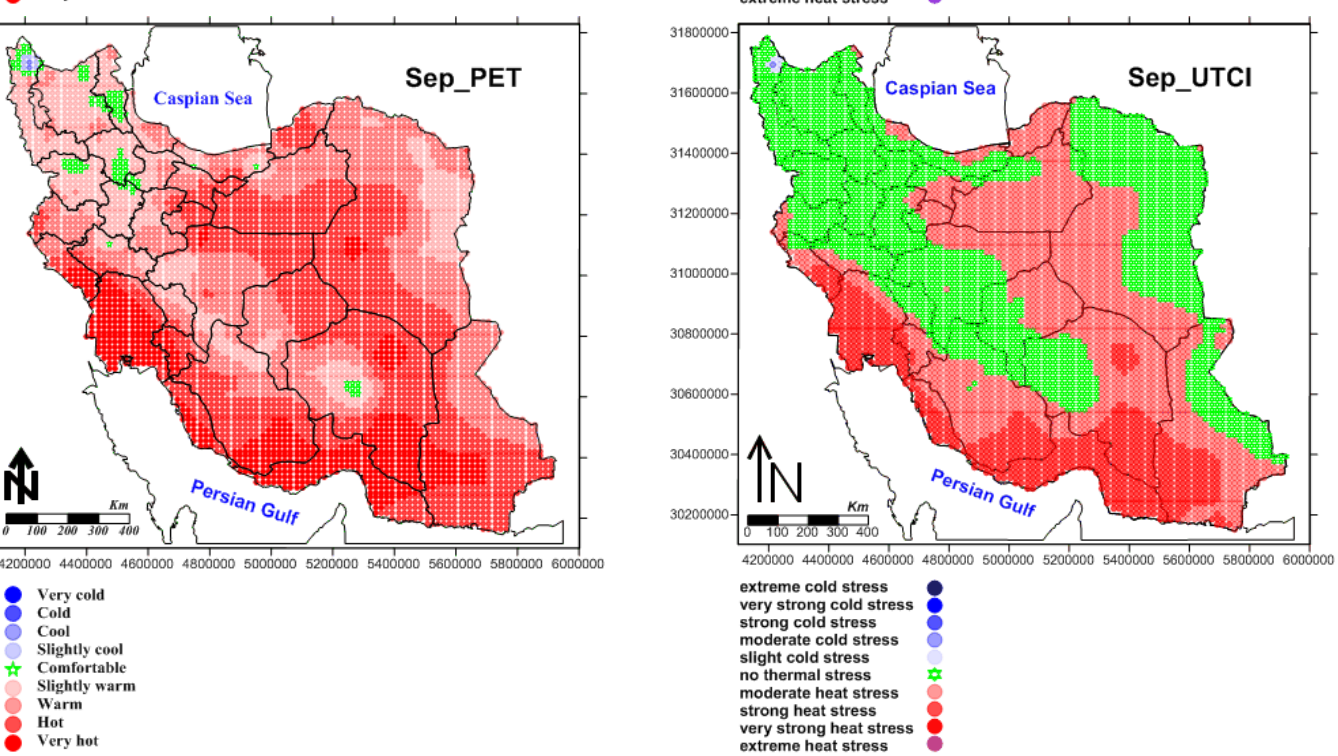

Figure 5. Iran's bioclimatic conditions in July, August and September 


\section{October}

With the onset of autumn in October, significant changes in Iran's bioclimatic conditions have occurred. In this month, limited parts of Iran are under slight cold stress $(0.7 \%)$ and moderate cold stress (less than $0.1 \%$ ). The province of west Azarbaijan and Kurdistan, Zanjan and Hamedan experienced such conditions. The most important bioclimatic characteristics of this month, is the lack of heat stress conditions in $79.1 \%$ of the country. Most parts of Iran compared to other months are in the range of climatic comfort. Cold stress conditions in the narrow strip of the southwest to the southeast can be seen. Moderate heat stress and strong heat stress was reported only in 18 and $2.1 \%$ of Iran. The increasing extent of no thermal stress on the one hand and reduced thermal stress on the other hand, are indicative of the start of the cold period. Based on PET, slightly cool and cold conditions can be seen in less than 0.10 of Iran. However, in October, cold and very cold conditions have not yet begun. Heat conditions in this month to the lower latitude and low-lying areas have receded. In fact, the highlands with high-latitude have moved towards cold conditions. In this month, slightly warm, comfortable and warm conditions were seen in 30.6, 23.7 and $22.3 \%$ of Iran, respectively. Very hot conditions are in less than $5.0 \%$ of Iran. Therefore, October, can be called a transitional month moving towards cold conditions (Fig. 6).
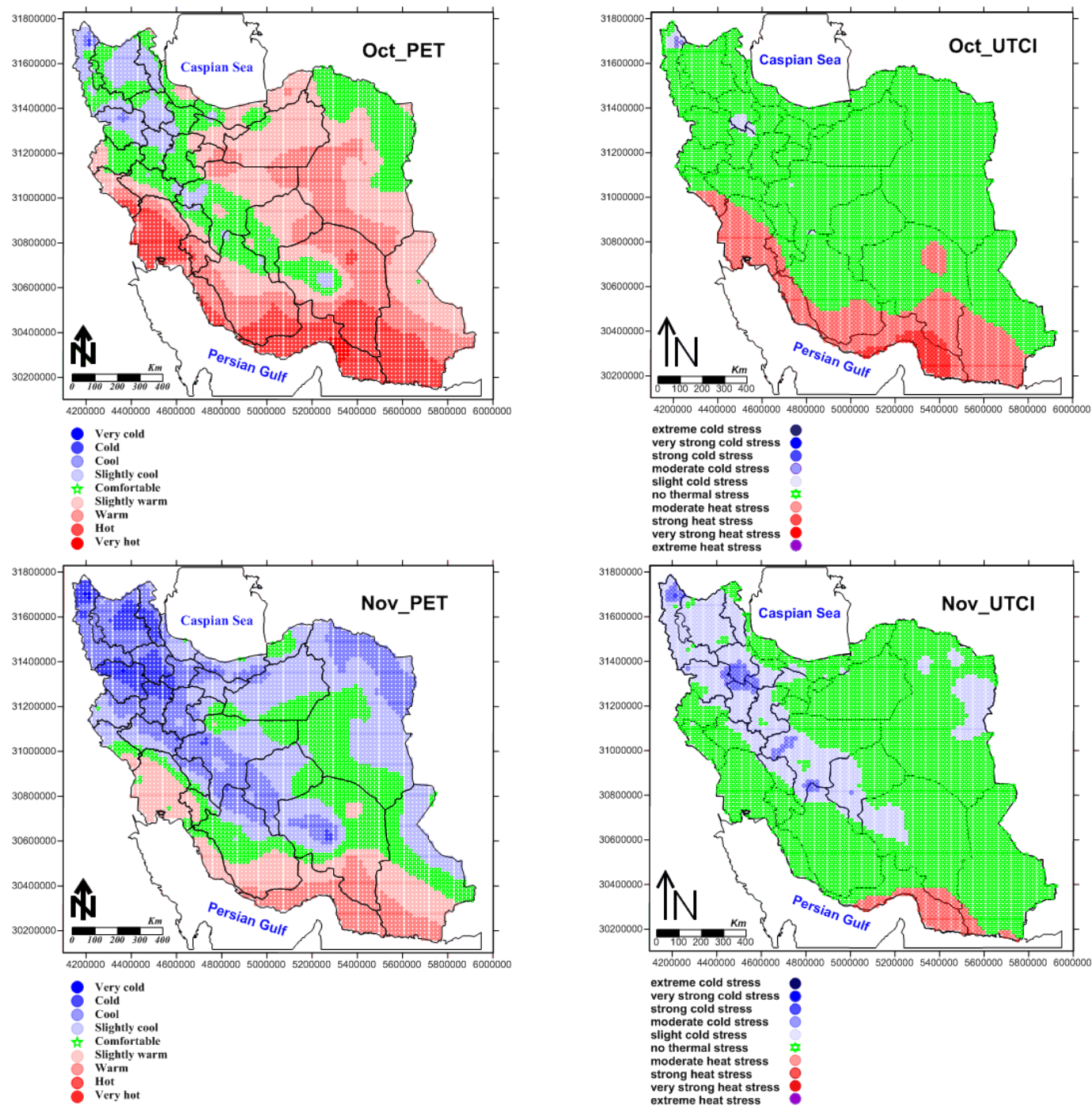

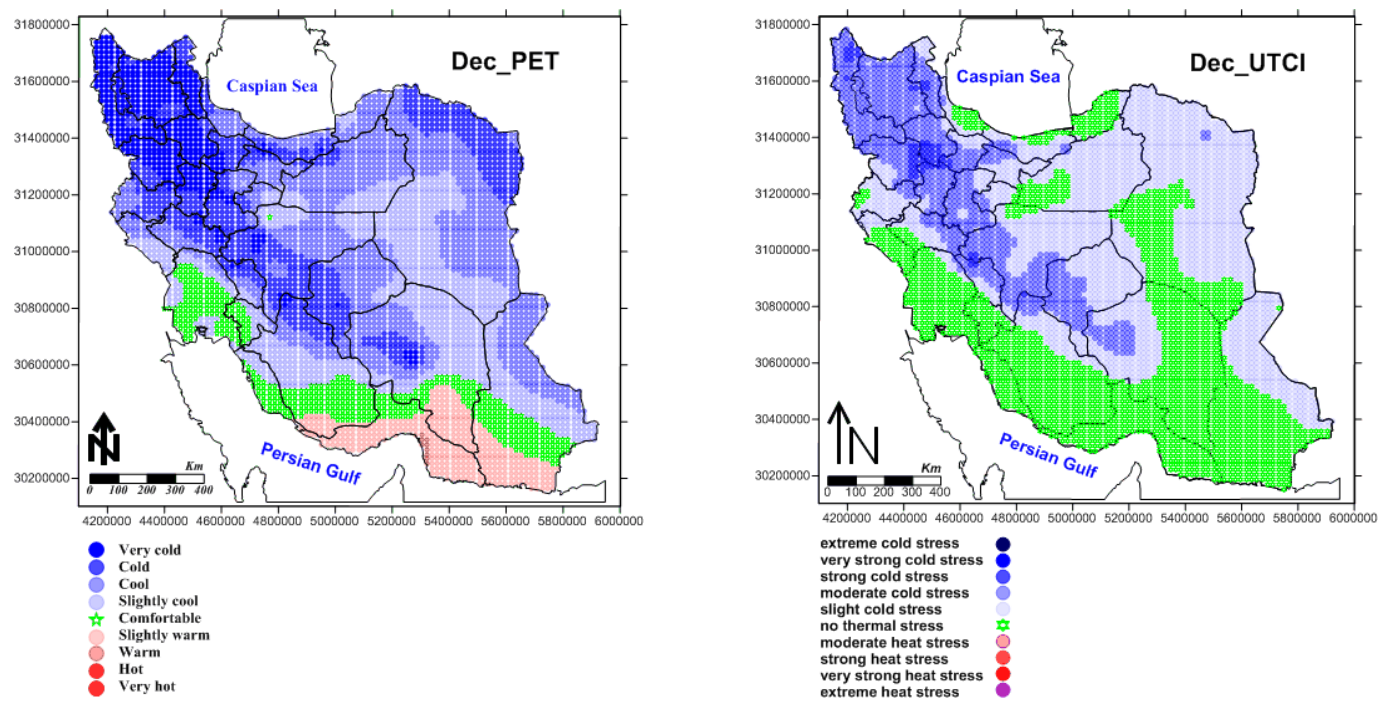

Figure 6. Iran's bioclimatic conditions in October, November and December

\section{November}

In November, only 3.3\% of the territory of Iran (including southern Iran) has reported heat stress conditions. In fact, with the exception of the southern coast, heat stress conditions with different intensities are not seen in Iran. In parts of the Khorasan province and from the northwest of Iran to Kerman province, slight cold stress and moderate cold stress dominates the region. What is obvious is that compared to October, conditions of heat stress and no thermal stress conditions have shown a significant decrease. Moreover, significant increase, especially in slight cold stress condition $(23.5 \%)$ and moderate cold stress $(1.9 \%)$ can be observed. Based on the PET index, the bioclimatic condition in November shows a major difference with October. In this month, very hot and hot conditions have left Iran and on the other hand very cold and cold conditions are reported only in about $5 \%$ of the region. Overall, in about $20 \%$ of Iran, slightly warm and warm conditions can be seen. Compared to October, in November, there is a slight increase in the expansion of thermal comfort (24\%). In this month 29, 24 and $22 \%$ of Iran respectively, is surrounded by slightly cool, comfort and cool conditions. Also thermal stress to the low latitudes and low-lying areas has been displaced (Fig. 6).

\section{December}

The Cooling trend in Iran that began in September has become more intense in December. In December, in no part of this country have heat stresses been experienced. In addition, thermal stress conditions of $71.3 \%$ in November decreased to $39 \%$ in December. In this month, no thermal stress conditions are experienced in low-lying areas and low latitudes especially in coastal areas as well as parts of the Caspian Sea. Overall, more than $60 \%$ of Iran has experienced cold stress with different intensities. Highlands and higher latitudes have more severe cold stress conditions. Temperature reduction in December continues based on the PET index. In this month, only $0.2 \%$ is in hot conditions and $7.9 \%$ of Iran was in slightly warm conditions. Therefore, any effect of hot and very hot conditions cannot be seen in Iran. On the other hand, very cold and 
cold conditions have shown a significant increase in December compared to April to November. In fact December, after the months of January and February, is the coldest month in Iran. In addition, significant reductions in thermal stress can be seen in this month. In this month, thermal stress can be seen in about $10 \%$ of Iran. Cold severity to the northwest of Iran and highlands is more. However, in some parts of the south coast, slightly warm conditions can still be experienced (Fig. 6).

\section{Discussion}

Iran is one of the largest countries that located in Middle East. Iran has an area of $1,648,195$ square kilometres. It lies between latitudes $24^{\circ}$ to $40^{\circ} \mathrm{N}$, and longitudes $44^{\circ}$ to $64^{\circ}$ E. Iran consists of the Iranian Plateau and it is one of the world's most mountainous countries, its landscape dominated also by rugged mountain ranges. Therefore, Iran's climate is very diverse ranging from arid and semi-arid, to subtropical along the Caspian coast and the northern forests. This study was performed with the aim of determining the thermal stress and bioclimatic conditions of Iran. Most of the researches in terms of bioclimatic conditions in Iran have been done within the cities and/or provinces. However, in the estimation of bioclimatic conditions of Iran, the different indices are used. Comparison of this research to other researches that have been conducted in different parts of the country shows there are slight differences in the estimation of bioclimatic conditions. Without a doubt, such differences may be caused by the type and volume of data and the different methods used. However, analysis of bioclimatic conditions in Iran is the most important feature of this research. The impact of bioclimatic conditions on thermal comfort in different areas of the world has been carried out recently, indicating the impact of urban bioclimatic on human morbidity (Schwartz et al., 2004; Nastos and Matzarakis, 2006), tourism potential and decision making (Didaskalou and Nastos, 2003; Hamilton and Lau, 2003), urban planning (Nikolopoulou and Lykoudis, 2006; Thorsson et al., 2007), and mortality (Analitis et al., 2008; Almeida et al., 2010). In general, the result of this research is almost in alignment with the work of Ramazani Gourbi (2010). Looking at the map of bioclimatic Iran, it can be said that in the eastern and western parts of the Gilan province, comfort conditions can be seen throughout the year. However, the eastern parts of this province have more thermal comfort. The results of this study have some differences to the research that Shakoor (2011) conducted on on Yazd. Shakoor believes that in the months of October, November and January, favourable climatic conditions exist in Yazd. The findings of this study are no in alignment with the findings of Ghavidel Rahimi and Ahmadi (2013). The results of this study are however in line with the studies of Tavoosi and Sabzi (2013) and Mohammadi (2014). However, there are the slight differences between findings of this study and other researches, a part or parts of Iran have studied. In these regions, temperatures rarely fall below freezing and the area remains humid for the rest of the year. To the west, settlements in the Zagros basin experience lower temperatures, severe winters with below zero average daily temperatures and heavy snowfall. The eastern and central parts of Iran are arid, with less than $250 \mathrm{~mm}$ of precipitation, and have occasional deserts. Average summer temperatures rarely exceed $38{ }^{\circ} \mathrm{C}$. The coastal plains of southern Iran have mild winters, and very humid, sultry and hot summers with annual precipitation of less than $350 \mathrm{~mm}$. Generally the results of this study showed that Iran's bioclimatic conditions are very diverse during the year. 
According to UTCI, all bioclimatic conditions (except extreme cold and extreme heat stress conditions) in a limited time and a small territory of Iran were at least experienced. In contrast to some areas experiencing cold condition in winter (with different intensities), some areas of Iran show a thermal comfort conditions which highlights the climatic diversity of the country as well as high tourism potential throughout the year. These regions are mostly located in south latitudes and Iran's lowland areas which display the lowest thermal stress conditions. In spring, cold stress and comfort conditions is reduced. However in this season, especially, thermal stress condition is prevalent in considerable parts of Iran, but heat stress conditions with different intensities is expanding. At the beginning of the summer the regions that have experienced thermal stress conditions have decreased. The results of this research reveal that heat stress with different intensities has been experienced in more than half of Iran. In late summer, heat stress in Iran will gradually decline. In the autumn, with the increasing cold stress and reducing heat stress, we can see the cooling process in Iran. The other results of this study showed that moderate cold stress and thermal stress conditions can be seen all year round. In fact, the existence and expansion of thermal comfort and generally bioclimatic conditions with different intensities at any time of year (in large or small parts of Iran), shows Iran's bioclimatic ability. The occurrence of simultaneous bioclimatic conditions also reflects the fact that Iran is a country of four seasons. This means, when many parts of Iran (northwest, west and northeast) are experiencing strong cold stress conditions in December, January and February, other parts of the country are experiencing comfort and moderate heat stress conditions. Such a contradiction in the bioclimatic conditions event is even in some provinces of the country. For example, very diverse bioclimatic conditions have been experienced in the months of June and July in the Isfahan province. Kerman province has this climate variety in August, September and December. Comparisons of the results of PET and UTCI indices showed that in some months of the year (such as January and February) there is very little difference between the estimated bioclimatic conditions in Iran. However, in March, April, May, September, October and November, there are considerable differences in bioclimatic conditions estimated by these indices.

Compared with previous studies of thermal stresses in other parts of Iran, the advantage of the method employed in this research is that the PET index is more understandable for people who (tourists) can assess the outdoor thermal condition based on their experience in an indoor environment (Farajzadeh et al., 2015; Roshan et al., 2018). About half the country is covered with mountains and moreover due to the vastness of Iran, it has various and different climates. Iran's climatic diversity in terms of spatial and temporal scale is visible. According to studies that published in Farsi, Iran is divided into several climatic regions. The south of Iran has very humid hot weather. Winters are very pleasant. Iranians travel to the south of Iran in winters; especially Kish and Gheshm islands have the best weather in winters. Therefore, the temperature difference in different parts of Iran can reach up 40 to 50 degrees in winter. Considering such explanations, we can say it seems that the PET index compared to the UTCI index showed a great ability in estimating Iran's bioclimatic conditions. In fact, the PET Index shows Iran's climatic diversity better than the UTCI index. Bioclimatic maps that are presented in this study can provide a good platform for doing a lot of planning, energy management, human activities such as tourism and even other environmental studies. Furthermore, the results of this study are important for government agencies to offer detailed tourism climate information to improve the success of the tourism industry. 


\section{Conclusion}

The evaluation of the bioclimatic conditions for Iran was carried out based on the analysis of the UTCI and PET indices. The results of this study showed that at the spatial and temporal scales Iran has different bioclimatic conditions. The results of this research have several applications in the fields of tourism, agriculture, medical, and architecture, etc. In general, bioclimatic maps in this research have a useful uses for decision makers on various levels, including health, tourism and regional planning. The results of this study suggest that the bioclimatic conditions of Iran during the year are very diversity. However, warm and very warm bioclimatic conditions in most cases have been experienced in the southern parts of Iran and areas with lower altitude. These regions are affected by heat stress in spring and summer seasons. Analysis of the bioclimatic conditions is subject of applied investigation among various scientists such as urban planners, climatologists, architects, and biologists. According to the studies mentioned in discussion section can be said that there are several research recommendations in the field of bioclimatic conditions in Iran. To better understand the bioclimatic conditions of Iran, the trend analysis of the Iran's bioclimatic conditions has been suggested. Also, the relationship between bioclimatic conditions and the rate of hospital admissions for cardiovascular disease in Iran can be the other topic for future research.

\section{REFERENCES}

[1] Almeida, S. P., Casimiro, E., Calheiros, J. (2010): Effects of apparent temperature on daily mortality in Lisbon and Oporto, Portugal. - Environmental Health 9(1): Article 12.

[2] Analitis, A., Katsouyanni, K., Biggeri, A. et al. (2008): Effects of cold weather on mortality: results from 15 European cities within the PHEWE project. - American Journal of Epidemiology 168: 1397-1408.

[3] Basarin, B., Lukic, T., Mesaros, M., Pavic, D., Dordevic, J., Matzarakis, A. (2018): Spatial and temporal analysis of extreme bioclimate conditions in Vojvodina, Northern Serbia. - Int. J. Climatol 38: 142-157.

[4] Blażejczyk, K., Epstein, Y., Jendritzky, G., Staiger, H., Tinz, B. (2012): Comparison of UTCI to selected thermal indices. - International Journal of Biometeorology 56: 515-535.

[5] Bröde, P., Fiala, D., Blazejczyk, K., Epstein, Y., Holmér, I., Jendritzky, G., Kampmann, B., Richards, M., Rintamäki, H., Shitzer, A., Havenith, G. (2009): Calculating UTCI Equivalent Temperature. - In: Castellani, J. W., Endrusick, T. L. (eds.): Environmental Ergonomics XIII. University of Wollongong, Wollongong, pp. 49-53.

[6] Caliskan, O., Cicek, I., Matzarakis, A. (2012): The climate and bioclimate of Bursa (Turkey) from the perspective of tourism. - Theor Appl Climatol 108: 417-425.

[7] Cendrowska, K. L. (2013): Assessment of bioclimatic conditions in cities for tourism and recreational purposes (A Warsaw case study). - Geographia Polonica 86: 55-66.

[8] Charalampopoulos, I., Tsiros, I., Chronopoulou-Sereli, A., Matzarakis, A. (2013): Analysis of thermal bioclimate in various urban configurations in Athens, Greece. Urban Ecosyst 16: 217-233.

[9] Dadbakhsh, M., Khanjani, N., Bahrampour, A., Haghighi, P. S. (2017): Death from respiratory diseases and temperature in Shiraz, Iran (2006-2011). - Int J Biometeorol 61: 239-246.

[10] Didaskalou, E. A., Nastos, P. T. (2003): The role of climatic and bioclimatic conditions in the development of health tourism product. - Anatolia 14(2): 107-126. 
[11] Eslami, A. R., Tirandaz, M. (2011): The use of GIS on bioclimatic zoning for tourism settlement (case study: Polroud basin, Guilan province). - Annals of Biological Research 2: 44-51.

[12] Farajzadeh, H., Matzarakis, A. (2009): Quantification of climate for tourism in the northwest of Iran. - Meteorol Appl 16: 545-555.

[13] Farajzadeh, H., Saligheh, M., Alijani, B., Matzarakis, A. (2015): Comparison of selected thermal indices in the northwest of Iran. - Natural Environment Change 1: 61-80.

[14] Frich, P., Alexander, L. V, Della-Marta, P., Gleason, B., Haylock, M., Klein Tank, A. M. G., Peterson, T. (2002): Observed coherent changes in climatic extremes during the second half of the twentieth century. - Clim. Res. 19: 193-212.

[15] Geletič, J., Lehnert, M., Savić, S., Milošević, D. (2018): Modelled spatiotemporal variability of outdoor thermal comfort in local climate zones of the city of Brno, Czech Republic. - Science of the Total Environment 624: 385-395.

[16] Ghavidel Rahimi, Y., Ahmadi, M. (2013): Estimation of climatic comfort in Tabriz. Geography and Development 33: 182-173.

[17] Givoni, B., Noghuchi, M., Saaroni, H., Pochter, O., Yaacov, Y., Feller, N., Becker, S. (2003): Outdoor comfort research issues. - Energy and Building 35: 77-86.

[18] Gulyas, A. (2005): Differences in human comfort conditions within a complex urban environment: a case study. - Acta Climatologica et Chorologica 38-39: 71-84.

[19] Gulyas, A., Matzarakis, A. (2007): Selected examples of bioclimatic analysis applying the physiologically equivalent temperature in Hungary. - Acta Climatologica et Chorologica 40-41: 37-46.

[20] Hamilton, J. M., Lau, M. A. (2005): The role of climate information in tourist destination choice decision-making. -Proceedings of the 17th International Congress of Biometeorology, Garmisch-Partenkirchen (Germany), 5-9 Sep 2005, pp. 608-611.

[21] Ichinose, T., Matuschek, O., Jing, Y. (2008): Biometeorology for tourism/recreation in Japan: a review. - Global Environmental Research 12: 123-128.

[22] Kalkstein, A. (2008): Geographical variations in seasonal mortality across the United States: a bio climatological approach. - A dissertation presented in partial fulfillment of the requirements for the degree doctor of philosophy, Arizona State University, UMI Number: 3319075.

[23] Kántor, N., Égerházi, L., Unger, J. (2012a): Subjective estimation of thermal environment in recreational urban spaces-Part 1: Investigations in Szeged, Hungary. - International Journal of Biometeorology 56(6): 1075-1088.

[24] Kántor, N., Unger, J., Gulyás, Á. (2012b): Subjective estimations of thermal environment in recreational urban spaces-Part 2: International comparison. - International Journal of Biometeorology 56: 1089-1101.

[25] Ketterer, C., Matzarakis, A. (2012): Development and application of assessment methods for thermal bioclimate conditions in Stuttgart. - ICUC8, 8th International Conference on Urban Climates, 6th-10th August, UCD, Dublin Ireland.

[26] Kovács, A., Németh, A., Unger, J., Kántor, N. (2017): Tourism climatic conditions of Hungary-present situation and assessment of future changes. - Journal of the Hungarian Meteorological Service 121: 79-99.

[27] Lecha Estela, L. B. (2008): Biometeorological classification of daily weather types for the humid tropics. - Int J Biometeorol 42: 77-83.

[28] Lin, T. P., Matzarakis, A. (2008): Tourism climate and thermal comfort in Sun Moon Lake, Taiwan. - International Journal of Biometeorology 52: 281-290.

[29] Lin, T. P., De Dear, R., Hwang, R. L. (2011): Effect of thermal adaptation on seasonal outdoor thermal comfort. - International Journal of Climatology 31: 302-312.

[30] Lise, W., Tol, R. S. J. (2002): Impact of climate on tourism demand. - Clim Change 55: 429-449.

[31] Maddison, D. (2001). In search of warmer climate? The impact of climate change on flows of British tourists. - Clim Change 49: 193-208. 
[32] Matzarakis, A. (2006): Weather- and climate-related information for tourism. - Tourism and Hospitality Planning and Development 3: 99-115.

[33] Matzarakis, A. (2008): Relevance of thermal bioclimate for tourism in Japan. - Global Environmental Research 12: 129-136.

[34] Matzarakis, A., Mayer, H. (1997): Heat stress in Greece. - Int J Biometeorol 41: 34. https://doi.org/10.1007/s004840050051.

[35] Matzarakis, A., Mayer, H., Iziomon, M. (1999): Applications of a universal thermal index: physiological equivalent temperature. - Int. J. Biometeor 43: 76-84.

[36] Matzarakis, A., Muthers, S., Koch, E. (2011): Human biometeorological evaluation of heat-related mortality in Vienna. - Theor Appl Climatol 105: 1. https://doi.org/10.1007/s00704-010-0372-x.

[37] Matzarakis. A; Rammelberg. J., Junk. J. (2013): Assessment of thermal bioclimate and tourism climate potential for central Europe, the example of Luxembourg. - Theor Appl Climatol 114: 193-202.

[38] Milošević, D., Bajšanski, I., Savić, S., Žiberna, I. (2016): Benefits of the environmental simulations for the urban planning process. - 4th eCAADe International Regional Workshop, Faculty of Technical Sciences, University of Novi Sad, May 19-20, 2016.

[39] Mohammadi, B. (2014): An estimation and spatio-temporal analysis of climatic comfort conditions in Kurdistan province. - Geographical Research Quarterly 113: 159-176.

[40] Mohammadi, B., Karimi, S. (2017): The relationship between thermal sensation and the rate of hospital admissions for cardiovascular disease in Kermanshah, Iran. - Theoretical and Applied Climatology. https://doi.org/10.1007/s00704-017-2332-1.

[41] Morgan, R., Gatell, E., Junyent, R., Micallef, A., Ozhan, E., Williams, A. (2000): An improved user- based beach climate index. - J Coast Conserv 6: 41-50.

[42] Nastos, P. T., Matzarakis, A. (2006): Weather impacts on respiratory infections in Athens, Greece. - International Journal of Biometeorology 50: 358-369.

[43] Nastos, P., Matzarakis, A. (2008): The effect of air temperature and the thermal index PET on mortality in Athens, Greece. - Proceedings 18th International Congress on Biometeorology, Tokio, 22-26 September 2008, pp. 1-4.

[44] Nikolopoulou, M. (2004): Outdoor Comfort. - In: Steemers, K., Steane, M. A. (eds.) Architecture and Variety: Environmental Perspectives. Spon Press, London.

[45] Nikolopoulou, M., Lykoudis, S. (2006): Thermal comfort in outdoor urban spaces: Analysis across different European countries. - Building and Environment 41: 14551470.

[46] Nikolopoulou, M.-H., Lykoudis, S. (2007): Use of outdoor spaces and microclimate in a Mediterranean urban area. - Building and Environment 42: 3691-3707.

[47] Potchter, O., Cohen, P., Lin, T. P., Matzarakis, A. (2018): Outdoor human thermal perception in various climates: A comprehensive review of approaches, methods and quantification. - Science of the Total Environment 631: 390-406.

[48] Pourvahidi, P., Ozdeniz, M. B. (2013): Bioclimatic analysis of Iranian climate for energy conservation in architecture. - Scientific Research and Essays 8: 6-16.

[49] Ramazani Gourbi, B. (2010): The zoning of human bioclimatic comfort for ecotourism planning in Gilan, Iran South Western of Caspian Sea. - Australian Journal of Basic and Applied Sciences 4(8): 3690-3694.

[50] Richards, M., Havenith, G. (2007): Progress towards the Final UTCI Model. - In: Mekjavic, I. B., Kounalakis, S. N., Taylor, N. A. S. (eds.) Environmental Ergonomics XII. Biomed, Ljubljana, pp. 521-524.

[51] Roshan, G., Yousefi, R., Kovács, A., Matzarakis, A. (2018): A comprehensive analysis of physiologically equivalent temperature changes of Iranian selected stations for the last half century. - Theoretical and Applied Climatology 131: 19-41.

[52] Ruuhela, R., Jylhä, K., Lanki, T., Tiittanen, P., Matzarakis, A. (2017): Biometeorological Assessment of Mortality Related to Extreme Temperatures in Helsinki Region, Finland, 
in 1972-2014. - International Journal of Environmental Research and Public Health 944: 1-19.

[53] Schwartz, J., Samet, J. M., Patz, J. A. (2004): Hospital admissions for heart disease: the effects of temperature and humidity. - Epidemiology 15: 755-761.

[54] Scott, D., Jones, B., McBoyle, G. (2004): Climate, Tourism and Recreation: A Bibliography. - University of Waterloo, Waterloo.

[55] Shakoor, A. (2011): Investigating biophysics and bioclimate effect on the health of tourists in Yazd Province using tourism climate index (TCI). - International Journal of the Physical Science 6: 6607-6622.

[56] Tavoosi, T., Sabzi, B. (2013): Assess the extent of climatic comfort zone Ilam province Evans index. - Geography and Urban Regional Planning 7: 21-34.

[57] Thorsson, S., Honjo, T., Lindberg, F., Eliasson, I., Lim, E. M. (2007): Thermal comfort and outdoor activity in Japanese urban public places. - Environment and Behavior 39: 660-684. 